\title{
ОСОБЕННОСТИ ФОРМИРОВАНИЯ ОСОЗНАННОЙ МОТИВАЦИИ ПРИ ДИСТАНЦИОННОМ ОБУЧЕНИИ ДЛЯ УСПЕШНОГО ОСВОЕНИЯ УЧЕБНОГО МАТЕРИАЛА НА ПРИМЕРЕ РАБОТЫ ПОДГОТОВИТЕЛЬНОГО ОТДЕЛЕНИЯ ФАКУЛЬТЕТА МЕЖДУНАРОДНОГО ОБРАЗОВАНИЯ
}

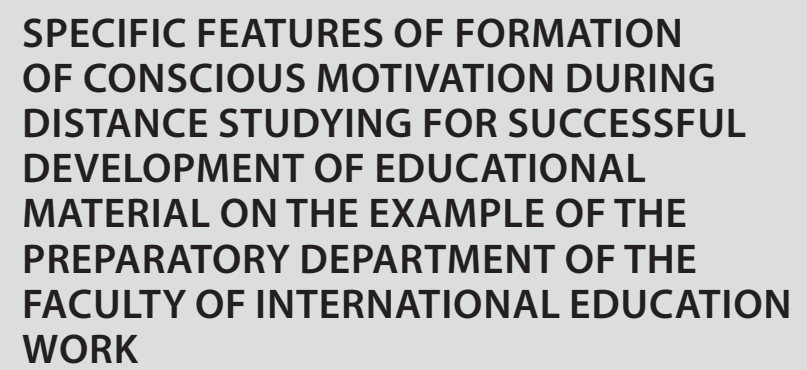

N. Bolokova

F. Pafova

Summary: The article is devoted to one of acute problems of modern education - distance education, as well as increasing the motivation of students in distance learning, the influence of various motivational components on the effectiveness of a foreign language online learning. The authors identify the main psychological barriers that reduce motivation and trust to the teacher, and suggest ways to overcome them. The research topic described in the article is relevant due to the importance of a thorough scientific and practical study of the students conscious motivation influence on the study results and the study of methods and techniques for increasing both motivation and trust both to the teacher and the other participants of the studying process.

The idea of the study can be determined as the systematization of existing pedagogical techniques to increase the motivation of students in distance studying and the search for new ones, as well as the analysis of factors that reduce trust in the educational team, both in the "teacher - student", and in the "student - group" connections. The main research methods used in this study are scientific analysis, observation and generalization. The key results of the study are to perform an algorithm of psychological and technical methods that help to achieve the anthropocentric concept of learning a foreign language on the example of studying Russian as a foreign language at the Preparatory Department. It is concluded that the algorithm of techniques and methods of the teacher, the involvement of students in a conscious process of co working helps to develop trusting relationships in the group and increase the cognitive motivation of students.

Keywords: distance studying, motivation, cognitive motivation, trust, foreign language, teaching techniques, teacher, student, online studying, psychological barriers, culture science.

\author{
Болокова Нуриет Кадырбечевна \\ К.филол.н., дочент, Майкопский государственный \\ технологический университет» \\ mamga9@mail.ru \\ Пафова Фатима Абрековна \\ К.филол.н., доцент, Майкопский государственный \\ технологический университет \\ fan1910@yandex.ru
}

Аннотация: Статья посвящена актуальной проблеме современного образования — дистанционной форме образования, а так же повышению мотивации обучающихся при дистанционной форме обучения, влиянию различных мотивационных компонентов на эффективность онлайн изучения иностранного языка. Авторами выявляются основные психологические барьеры, снижающие мотивированность и доверие к педагогу, и предлагаются способы их преодоления.

Актуальность темы исследования, описанного в статье, обусловлена важностью тщательного научного и практического исследования влияния осознанной мотивированности обучающихся на результаты обучения и изучение методов и приемов повышения как мотивированности, так и доверия, не только к педагогу, но и к другим участникам образовательного процесса. Цель исследования можно определить, как систематизацию существующих педагогических приемов для повышения мотивации обучающихся в режиме дистанционного обучения и поиск новых, а также анализ факторов, снижающих доверие в образовательном коллективе, как в связке «педагог - обучающийся», так и в связке «обучающийся - группа». Основные методы исследования, используемые в данном исследовании - научный анализ, наблюдение и обобщение. Ключевыми результатами исследования является выведение алгоритма психологических и технических приемов, помогающих добиться успешной реализации антропоцентрической концепции изучения иностранного языка на примере изучения русского языка как иностранного на подготовительном отделении. Сделаны выводы о том, что выведение алгоритма приемов и методов педагога, вовлечение обучающихся в осознанный процесс совместной работы помогают построить доверительные отношения в группе и повысить когнитивную мотивацию обучающихся.

Ключевые слова: дистанционное обучение, мотивация, когнитивная мотивация, доверие, иностранный язык, методика преподавания, педагог, обучающийся, онлайн обучение, психологические барьеры, культурология.

Грант Министерства просвещения Российской федерации на реализацию мероприятий, направленных на полноценное функционирование и развитие русского языка, ведомственной целевой программы «Научно-методическое, методическое и кадровое обеспечение обучения русскому языку и языкам народов Российской Федерации» подпрограммы «Совершенствование управления системой образования» государственной программы Российской Федерации «Развитие образования» 
И стория появления и развития дистанционного обучения насчитывает не одно десятилетие: в конце 19 века в Швеции и Англии предлагали обучение по почте, в 40-х годах 20 века в США создание радио способствовало активному развитию дистанционного обучения, появление глобальной сети Интернет и его доступность привели к тому, что образование стало возможным получать не покидая рабочего места или дома. Массовое применение дистанционного обучения началось в 80-х годах 20 века и получило развитие во многих странах [1, с.200]. Однако, дистанционные курсы и обучения были рассчитаны на людей с ограниченными возможностями или для людей, получающих дополнительное профессиональное образование или переподготовку, а посему рассматривались как дополнительная форма обучения, наряду с очной «живой» формой. В таких условиях данная парадигма обучения имела неоспоримые достоинства, так как давала обучающемуся возможность выбирать удобное для него время, место и скорость усвоения материала. Появление в 2020 году новой инфекции привело к переходу большинства университетов на дистанционную форму обучения, что потребовало от ученых, исследователей и педагогов изучить данный вопрос и выявить достоинства и недостатки подобного обучения. За прошедший год было проведено большое количество исследований $[2,3,4]$, которые выявили недостатки и достоинства дистанционной системы обучения как основной, так как ранее рассматривалась только дополнительная функция такого вида обучения, которая в силу своей эргономичности и мобильности показывала только плюсы. Однако если говорить о дистанционном образовании как об основном, то возникает много вопросов, имеющих отношение не только к процессу преподнесения материала, но и к приемам мотивации обучающихся. Ранее мы уже рассматривали роль мотивации и доверия к преподавателю в процессе интенсивного усвоения иностранного языка [5, с.54], но в аудиторных условиях «живого» общения. В данной статье мы планируем вывести алгоритм действий преподавателя для снятия психологических барьеров, возникающих у обучающегося в процессе дистанционного изучения предмета. К таким барьерам мы относим технические неполадки, слабую самоорганизацию обучающихся, размытость личности и образа преподавателя, снижение доверия в группе и к педагогу, отсутствие языковой среды и, как следствие, краткосрочной мотивации (если обучающийся не находится на территории изучаемого языка), низкая долгосрочная мотивация, невозможность погружения в культурную среду, что всегда приводит к потере интереса к познанию культурного наследия нации через язык.

Преодоление барьеров требует от педагогов пересмотра методов работы и адаптацию к условиям новой педагогической реальности, где для успешного функционирования требуется учитывать особенности вос- приятий информации новым поколение обучающихся. Здесь следует упомянуть теорию поколений Нейла Хоува и Вильяма Штрауса, определяющую новое поколение как «электронных людей», для которых мобильные телефоны, различные гаджеты и интернет стали привычной действительностью. В систему ценностей этой группы уже включены такие понятия как гражданский долг и мораль, ответственность, но при этом на первый план выходит немедленное вознаграждение, стремление к комфортным условиям труда, высокая мобильность» [6. C.5] Интернет и гаджеты являются для нового поколения родной средой, однако привычная для современной молодежи форма подачи информации соцсетей и сайтов существенно отличается от преподнесения материала педагогами, особенно вузов, по своей красочности, доступности и объему. Обучающиеся ожидают не только красочных, лаконичных видео или презентации, но и рациональных знаний, усвоение которых приведет к экономическому процветанию. Концепция Дж. Мокир «полезного знания» отображает процесс конкретизации и прагматизации целей образования [7. С.8]. Получив теоретическую лекцию, содержащую термины, классификации, таблицы, обучающийся задается вопросом целесообразности данной информации для его дальнейшего профессионального роста и развития. К тому же, такой вид информации требует концентрации внимания дольше 40 секунд и требует самоорганизации и самоконтроля. Вследствие этого мотивация студентов снижается, что влечет за собой и снижение качества образования, а в некоторых случаях и отказ от дальнейшего обучения. Зарубежные коллеги проводили исследования в области групповой работы и социального взаимодействия обучающихся при дистанционном обучении, и подчеркивают, что для самих студентов в рамках обучения в сотрудничестве (особенно в рамках онлайн-обучения) важную роль играют психологическая дистанция и социальное взаимодействие. Чувство связи положительно влияет на их самомотивацию и готовность к групповой работе [8. С. 331].

Доброжелательность и терпимость участников дистанционного обучения друг к другу - важнейшие психологические условия для благоприятного развития всего процесса [9, С. 272].

Группа студентов Санкт-Петербургского политехнического университета Петра Великого также провела анализ готовности преподавателей и студентов к дистанционной форме обучения, включающий опрос студентов. Среди основных преимуществ дистанционного формата студенты выделяют экономию времени - 100\%, комфортные условия - 64,7\%, развитие навыков самоконтроля - 29,4\%, а также повышение уровня мотивации - 29,4\%. К основным отрицательным аспектам студенты относят технические проблемы, что составляет наибольший процент - 76,5\%, а также отсутствие моти- 
вации - 52,9\%, нехватку живого общения с преподавателями - 47,1\%, и наконец трудность с планированием своего свободного времени - 41,2\% [10.с.99]. Как видно из исследований важность мотивации и общения с преподавателем осознанное признание самих студентов, как и нехватка этих составляющих в дистанционной форме обучения. Проблема выявлена и признана обоими участниками коллаборации «педагог - обучающийся» и далее необходимо разработать стратегию поведения, адоптировать методику преподавания и выявить протокол внешних и внутренних психологических установок. Появившийся вследствие пандемии опыт преподавания русского языка как иностранного онлайн в группе «с нуля» и полученный результат, позволили выявить следующие способы повышения мотивации обучающихся и доверия к педагогу: - Признание равноправными, командными отношениями «педагог - обучающийся». Признание педагогом несовершенства его познаний в области работы на обучающих платформах и с другими техническими девайсами вовлекает обучающихся в осознанный процесс успешной коллаборации, помощи педагогу и дает понимание важности и сложности процесса перехода на новый формат обучения. Чувство вовлеченности и ответственности мотивирует и способствует правильной самоорганизации, так как несет элемент контроля самостоятельной деятельности со стороны педагога;

- Объяснение студентам целей, задач и методов обучения для формирования осознанной мотивации. Ранее мы уже обращались к концепции «полезного знания» и понимаем, что обучающиеся ожидают лаконичной сжатой информации, которая пригодится им на практике сразу же, а не классификаций, определений и систем, ведущих к долгосрочному и полному пониманию изучаемого предмета. Объяснение педагогом целей и задач изучения теоретического материала ведет к осознанному изучению и анализу, пониманию и принятию важности фундаментальных знаний;

- Выработка четкой структуры урока и протокол поведения обучающегося при технических неполадках. Одним из главных врагов дистанционного образования, которому отведена ведущая позиция в рейтинге недостатков, являются технические неполадки, к которым относятся слабое интернет соединение, плохое обеспечение обучающихся компьютерами или ноутбуками. Педагог может снизить отрицательное демотивирующее влияние этих аспектов на итоговый результат, выстроив четкую структуру занятия и разработав протокол действий на случай временного отключения от сети.

- Наличие культурологических атрибутов на каждом занятии. Онлай обучение дает возможность привлекать культурологический и страноведческий материал легким нажатием кнопки или ссылки, не требует дополнительного оборудования, однако раскрывает неограниченные возможности погружения обучающихся в культурологическую и языковую среду. Для выработки ощущения реальности и причастности у обучающихся, педагогу следует использовать русские национальные атрибуты для фона экрана; в начале занятия на время сбора участников рекомендуем включать традиционные и популярные песни;

- Проведение совместных экскурсий, прогулок и праздников. Ключевое место занимает вводная онлайн экскурсия по университету, включающая показ мест отдыха и досуга студентов, а также фотографии предшествующих групп во время занятий или во время проведения университетских и городских мероприятий. Видео и фотоматериал города, в котором находится университет, с указанием достопримечательностей мотивирует обучающихся, формируя ощущение реальности и достижимости цели. Совместное проведение праздников ограничивается подготовкой обучающимися проектов-презентации к их национальным праздникам и совместное обсуждение традиции и кухни, дни рождения рекомендуем тоже «отмечать» совместным просмотром некоторых фотографий именинника, поздравлениями от каждого участника группы и обсуждением планов проведения праздничного дня;

- Поощрение общения и взаимопомощи обучающихся во внеурочное время. Педагогу следует уделять внимание общению обучающихся, стимулировать помощь более «сильных» студентов более «слабым», давать задания для совместного выполнения или для взаимоконтроля. При отсутствии одного из обучающихся педагогу следует делегировать задание узнать о причинах отсутствия другим обучающимся, что спровоцирует личное общение и благоприятно скажется на формировании доверительных отношений в группе;

- Расширение концепта «педагог» до понятия «наставник - живой человек». В аудитории во время «живого общения» обучающиеся формируют образ педагога, основываясь на наблюдениях за педагогом в различных ситуациях. Внешний вид, невербальный язык тела, энергия, идущая от педагога, общение с коллегами, все это формирует как положительный, так и отрицательный образ личности педагога. Положительность или отрицательность данного образа зависит от внутренних психологических установок обучающегося, его культурологической картины мира. В режиме дистанционного общения педагог заключен в рамки одного из «окошек» и теряет свою авторитетную позицию, лишен возможности использовать язык тела, силу голоса. В таких условиях обучающийся теряет ощущение реальности существования 
педагога, что не может не сказываться на его когнитивной мотивации. Приветствуется выход за рамки формального общения, предоставление обучающимся контролируемого доступа к некоторым аспектам личной и профессиональной жизни педагога;

- Обеспечение легкого доступа к учебным ресурсам и возможность восполнить пропущенный (технические неполадки) материал. Все учебные материалы урока следует предоставлять обучающимся в начале занятия, обозначив материал для самостоятельной работы на случай технических неполадок. Следует дублировать задания в группе ватцап, так как мессенджеры требуют меньше интернет ресурсов, чем обучающие платформы, а возможность быть на связи с группой помогает студентам не терять нить и последовательность занятия, создает психологически комфортную обстановку и формирует доверие обучающегося к педагогу и группе;

- Наличие своевременной и персонализированной обратной связи. Частичное или полное отсутствие эмпатии и рефлексии в процессе перепи- ски и обезличенной электронной коммуникации преподавателя со студентами - ещё один фактор, способствующий возникновению психологических трудностей [11, с. 309]. Как и многие приемы работы онлайн, этот пункт энерго и времязатратен, но необходим, особенно на начальном этапе работы с группой, так как формирует у обучающихся правильную концепцию дистанционного образования, ощущение личного общения с педагогом и помогает самоорганизации, а понимание ошибок и способов их устранения способствует когнитивной мотивации;

- Наличие позитивного заряжающего настроя у педагога. Да да, только позитивно заряженный педагог может мотивировать обучающихся на достижения и успехи, поэтому установите комфортный для вас режим работы, выделив определенное время на обратную связь с группой и на полноценный отдых от работы. Недолгие релаксирующие техники и физические зарядки помогут сохранять бодрый рабочий настрой; правильно организованное комфортное рабочее место так же необходимо.

\section{ЛИТЕРАТУРА}

1. Файзализода Б.Ф. История развития дистанционного обучения и современные направления в образовании // Вестник таджикского национального университета. 2019. № 6.С. 196-203.

2. Наумова Т.А., Неборский Е.В., Вытовтова Н.И. и др. Дистанционное обучение как средствообеспечения доступности профессионального образования для лиц с особыми образовательными потребностями // Alma Mater (Вестник Высшей школы). 2019. № 2. С. 61-66.

3. Бутенас В.Д., Редькина Т.М. Перспективы дистанционного обучения в образовательных организациях высшего образования // Colloquium-Journal. 2020. № 13-5. C. 5-7.

4. Бурнашева Л.Ю. Дистанционное обучение и его роль в современном мире. Colloquium Journal. 2020. № 10-5. С. $32-34$.

5. Болокова Н.К. Три аспекта в обучении русскому языку как иностранному: доверие - мотивация - говорение. Вестник майкопского государственного технологического университета. 2018. №3. С.52-59.

6. Зайцева Н.А. Теория поколений: мы разные или одинаковые? Н.А. Зайцева//Российские регионы: взгляд в будущее. - 2015. - №2(3). - Режим доступа: http:cyberleninka.ru/article/n/teoriya-pokoleniy-my-raznye-ili-odinakovye\#ixzz4W3EESDLg).

7. Мокир Дж. Дары Афины : исторические истоки экономики знаний [The Gifts of Athena : Historical Origins of the Knowledge Economy] / Дж. Mокир // Экономическая социология. - 2012. - Вып.4, Т.13. - С. 81- 94.

8. Hyo-Jeong So, Thomas A. Brush. Student perceptions of collaborative learning, social presence and satisfaction in a blended learning environment: Relationships and critical factors. Computers \& Education. 2008. № 51. P. 318-336.)

9. Теория и практика дистанционного обучения: учеб. пособие для студ. высш. пед. учеб.заведений / Е.С. Полат, М.Ю. Бухаркина, М.В.Моисеева; под. ред. Е.С. Полат. - М.: ИЦ «Академия», 2004. - 416 с.

10. Курышева Д.Д., Мещанова Д.Д., Шергина В.Д. Анализ готовности студентов и преподавателей к учебному сотрудничеству в условиях дистанционного обучения // Вопросы методики преподавания в вузе. 2020. Т. 9. № 35. C. 91-103. D0I: 10.18720/HUM/ISSN 2227-8591.35.09).

11. Фадеев Е.В. Организационные и психологические проблемы дистанционного обучения //Мир науки, культуры, образования. - 2017. - № 3 (64). - С. 308 -310 . 